\title{
Agglomeration economies and evolving urban form
}

\author{
Genevieve Giuliano ${ }^{1}$ · Sanggyun Kang ${ }^{2}$ - Quan Yuan ${ }^{3}$
}

Received: 20 June 2019 / Accepted: 11 November 2019 / Published online: 25 November 2019

(c) Springer-Verlag GmbH Germany, part of Springer Nature 2019

\begin{abstract}
Agglomeration economies are a fundamental explanation for the existence of cities. Spatial clustering allows for a variety of external benefits such as labor pooling, sharing of suppliers, and specialization; these in turn contribute to increased productivity and economic growth. Over the past several decades, the strength and nature of agglomeration economies have come into question. In the 1980s, it was argued that information and telecommunications technology reduced the need for physical proximity, and hence the value of agglomeration economies. Reduced agglomeration economies would explain the decentralization of economic activity and decline of central cities. We are now fully in the era of the information economy, with smart phones, cars, buildings, and appliances merging into the Internet of Things. At the same time, we observe the re-emergence of some downtowns and the continued growth of megalopolises around the USA, despite rising congestion. This essay traces the role and nature of agglomeration economies in the evolution of urban form.
\end{abstract}

Keywords Agglomeration economies · Employment centers · Spatial clustering · Urban form · Los Angeles

JEL Classification R110 $\cdot$ R120

Genevieve Giuliano

giuliano@usc.edu

1 Department of Urban Planning and Spatial Analysis, University of Southern California, Los Angeles, CA 90089, USA

2 Department of Logistics Research, The Korea Transport Institute, Sejong-si 30147, Republic of Korea

3 Department of Traffic Engineering, Tongji University, Shanghai 201804, China 


\section{Introduction}

The observation that large metropolitan areas are the source of most innovation and of greater economic productivity was made centuries ago, first by Smith (1776), and later by Marshall (1890). Their arguments included specialization, sharing of intermediate suppliers, and knowledge sharing, all made possible by large numbers of firms and workers clustered together at high density.

Agglomeration economies are the external benefits firms receive from co-location. In theory, if external benefits are greater than the added costs of higher rents, wages, and transport costs that agglomeration generates, there would be geographic clustering. If the opposite were the case, firms would disperse to places with lower costs. In reality, the high cost and geographically fixed nature of the built environment (infrastructure systems, buildings) would mitigate against rapid changes in urban form in response to changes in the nature of agglomeration economies. However, over time, changes in agglomeration economies should be observable via changes in the density and distribution of economic activity.

Over the past several decades, the strength and nature of agglomeration economies have come into question. It was argued that information and telecommunications technology reduced the need for physical proximity, and hence the value of agglomeration economies. Futurists predicted the dissolution of the city (Webber 1968; Pascal 1987; Fathy 1991). Reduced agglomeration economies would explain the decentralization of economic activity and decline of central cities observed in the last decades of the twentieth century (Downs 1997; Glaeser et al. 2001a, b). More recently, it has been argued that agglomeration economies work at two levels: metropolitan and sub-metropolitan, hence explaining increased polycentricity of metropolitan areas (Agarwal et al. 2012). Polycentricity has been widely studied and documented. ${ }^{1}$ We are now fully in the era of the information economy, with smart phones, cars, buildings, and appliances merging into the Internet of Things. At the same time, we observe the re-emergence of some downtowns and the continued growth of megalopolises around the USA, despite rising congestion. Do agglomeration economies continue to be a significant factor in metropolitan spatial structure? Is the nature of agglomeration economies changing?

This essay reviews the role and nature of agglomeration economies over the past few decades. We begin with a review of the nature of agglomeration economies as articulated by Krugman, Duranton, Puga, and others (e.g., Krugman 2011; Duranton and Puga 2004; Puga 2010). We add another factor to their list: amenity value. We then discuss the arguments for and against the continued significance of agglomeration economies, as well as their changing nature. Using a case study of the Los Angeles region, we present some recent empirical evidence of agglomeration associated with different types of sub-metropolitan industry clusters. The essay concludes

\footnotetext{
1 Examples include: Craig and Ng (2001), Craig et al. (2016), Forestall and Greene (1997), GarciaLópez (2010), Giuliano and Small (1991), Lee (2007), McMillen (2001) and Redfearn (2007). For a summary, see Agarwal et al. (2012).
} 
that agglomeration economies — both regional and local—are likely to continue to be a significant factor in urban spatial structure.

\section{The role and nature of agglomeration economies}

Following the classification of Duranton and Puga (2004), the causal mechanisms of agglomeration economies can be described in three categories: sharing, matching, and learning.

\subsection{Sharing}

Sharing economies include sharing of infrastructure, facilities, suppliers, and workers. Infrastructure, especially network-based infrastructure, is characterized by large returns to scale. Transport and telecommunications infrastructure becomes more valuable as the density of the network increases. Large upfront costs incentivize sharing, while network economies make sharing beneficial to the firm. Infrastructure is also characterized by indivisibilities. Half a bridge serves no purpose; hence, a critical mass is often required for key links in networked facilities. Graham and Marvin (1996) note the complementarity of infrastructure systems: the most dense and extensive information and communications technology (ICT) networks are overlaid upon the most dense and extensive transport and energy networks.

Sharing of intermediate inputs, namely suppliers and workers, is facilitated by size and density. As the size of a given industry sector increases, so does the opportunity for intermediate suppliers to offer goods and services. Larger cities allow for more specialization, which in turn allows for more efficient supply of intermediate goods. Complementarity across industry sectors allows for flexibility of supply, as suppliers are able to moderate volatility within specific industry segments. Evidence of input sharing has been demonstrated by Rosenthal and Strange (2001), Ellison et al. (2010) and Holmes (1999).

Labor pooling works in a similar way; the larger the labor pool, the more diverse and specialized it can become. Labor pool sharing has been demonstrated by Overman and Puga (2010). It is observed empirically that the largest metro areas have the most diverse workforce (Backman and Kohlhase 2013; Rauch 1993). Not only does the large metro area generate a market for niche labor (e.g., actors or opera singers), it allows for specialization within labor categories (e.g., from computer programmer to software specific programmer) that enhances labor productivity. Labor pooling is beneficial for both firms and workers. A large labor force allows the firm to size the labor force to its current demand, for example by hiring temp workers for surges in demand. It also mitigates against rising wages in response to increased demand, because total labor supply is likely to be less affected by the volatility of any given sector. At the same time, the worker benefits from many job opportunities so that he/she can move across industry segments as demand ebbs and flows. Finally, the entire local economy becomes more productive by being able to absorb sector specific volatility. 


\subsection{Matching}

If labor and supplier markets are large and diversified, it follows that better matches between employers and employees, or between firms and intermediate suppliers will take place. Better labor force matching reduces costs by increasing work tenure, reducing training costs, and reducing the probability of bad matches. Better intermediate supplier matching assures the best possible input and reduces unreliability costs of suppliers (because the firm can easily find a substitute). Search costs are also reduced, because there is a higher probability of appropriate match, and the number of possible good matches increases. One example of match benefits is the tendency of dual career households in highly specialized markets (say university professors) to locate in the largest metro areas. Matching benefits were demonstrated by Finney and Kohlhase (2008) in the case of job mobility of young men, Coles and Smith (1998), albeit in a highly specialized market (employees for new economics Ph.Ds), and by Costa and Kahn (2000) for dual career academics.

\subsection{Learning}

Jacobs (1961) was among the first to link the serendipity of random encounters facilitated by diverse, high density environments to innovation and economic productivity gains. In the more recent literature, it is argued that knowledge exchange, both formal and informal, is critical to innovation in rapidly changing industries such as high tech or finance (Graham and Marvin 1996; Castells and Hall 1994). Duranton and Puga (2001) argue that new firms go through a learning process regarding the best way to operate, and the most learning opportunities are available in large, diverse metro areas. Glaeser (1999) applies a similar idea to young workers: young workers migrate to the largest cities because of the learning opportunities associated with interactions with experienced workers. A common method for examining learning agglomeration benefits is through patents. These studies show that patents are correlated with city size (e.g., Jaffe et al. 1993).

\subsection{Amenity value}

Agglomeration economies may also derive from other factors. Glaeser et al. (2001a, b) articulate the concept of "Consumer City." Urban residents receive external benefits in the form of more and diverse consumption choices, from the boutique coffee purveyor to one-off originals of a local dress designer. Large agglomerations of consumers support niche markets of all kinds. As with the case of firms receiving agglomeration benefits, residents are willing to pay higher rents or receive lower wages in exchange for such benefits. If external benefits exist on the consumer side, agglomeration economies will persist whether or not the conventional forms discussed above are sufficient.

Related to consumer city is the argument that high-human capital workers demand high amenity places to live: places with cultural attractions, exciting 
night life, high-quality public services, and a rich variety of consumption alternatives. Since high-human capital workers are very valuable to the firm, firms will follow these workers and locate in high amenity places (e.g., Florida 2002, 2014; Kotkin 2000). Again, the implication is that conventional sources of agglomeration economies need not be net beneficial in order for agglomeration to occur.

\section{Arguments for and against}

Should agglomeration economies change or decline in the information economy? The surge of Information and Telecommunications (ICT) technology that took place in the 1980 s led to a lively debate as to whether agglomeration economies would increase or decrease with the rise of ICT and the information sector in the global economy. On the one side were those who declared the "death of distance" (Cairncross 1997). ICT would make information exchange effectively free, hence all but eliminating agglomeration benefits. Books with titles like City of Bits (Mitchell 1996) predicted a fragmented and dispersed metropolis. On the other side were those who argued that the information sector is at least as dependent on proximity as other industries. They argued that growth of the information sector would increase agglomeration economies (e.g., Gottman 1982; Gillespie 1992).

Theoretical arguments for declining agglomeration economies include (1) the increasing substitutability of ICT for physical presence; (2) shift to an information-based economy; and (3) declining transport costs. If information can be exchanged easily by virtual means, the demand for face-to-face encounters declines, and the willingness to pay for face-to-face should also decline. Firms then have the choice to locate in lower rent, less accessible places, or bid down the rent for more accessible locations, because accessibility is less valuable than it was before. The rapid suburbanization of population and jobs in the 1970s and 1980s, and particularly the shift of back office activity facilitated by ICT, could be interpreted as reflecting the declining value of agglomeration economies (Glaeser et al. 2001a, b; Audirac 2005). The second point is based on the assumption that the information sector is less dependent on face-to-face, sharing, or matching. The third point reflects the historical trend that transport costs have declined continuously through the twentieth century, making it faster and cheaper to overcome distance. The decline in transport costs has historically been associated with declining urban densities (Muller 2017).

The arguments for concentration can be discussed analogously. Theory suggests several reasons to believe that agglomeration economies may influence urban structure as much in the "new economy" as they did in the old economy. Using Duranton and Puga's (2004) three categories, it can be argued that information-based firms also benefit from sharing of local infrastructure, skilled labor pools, and intermediate suppliers; and from better matching. Moreover, the pace of innovation and knowledge creation throughout the economy should make proximity even more valuable as access to key players (innovators, venture capitalists) becomes more important. 


\section{Agglomeration at different scales}

The theoretical literature does not address the geographic scale of agglomeration economies. It is implicit that agglomeration economies operate at the "city" level, meaning at the metropolitan level. However, large metropolitan areas are not monocentric; they are polycentric, suggesting that agglomeration economies are not uniform within metro areas. Some have argued that as a result of reduced transport and communication costs, agglomeration benefits have become regional in scope; the metropolitan area itself is the source of external economies. If so, location anywhere within the metro area generates the same benefits, and hence, employment will disperse (e.g., Castells 1989; Gordon and Richardson 1996; Lang and Lefurgy 2003). However, we continue to observe spatial variation in density and land prices within metro areas. Are these concentrations simply the result of path dependency, or are agglomeration economies still at work at the sub-metropolitan level?

\subsection{Agglomeration at the sub-metropolitan level}

Multiple agglomeration clusters within large metropolitan areas make sense. Multiple clusters, each with their own location, size, and industry mix, provide firms with many choices. All else equal, firms should be better able to find the optimal location that provides the preferred level of sharing, matching, and learning benefits. If there were just one cluster (a monocentric city), land price, density, and congestion would be very high, as in the case of Tokyo or Paris. ${ }^{2}$ The only choice is where to locate within the center.

In previous work, ${ }^{3}$ my colleagues and I developed several arguments in support of sub-metropolitan agglomeration economies (Agarwal et al. 2012). The first is the Jacobs (1961) argument that dense and diverse neighborhoods are a necessary condition for the creative milieu, because creativity is derived from informal networks and serendipitous exchanges. That is, physical proximity benefits take place at a fine spatial scale.

The second is the volume, access, and time sensitivity of information in the knowledge economy. In a fast moving and ever-changing economy, immediate access to information of all sorts is essential. With huge volumes of information to process, information "mediators"- those who have access and process flows of information-become important. Thus, access to the manager who knows what products are under development, which venture capital proposals are in process, etc., becomes critically important. ICT tools may in fact reinforce the value of close proximity by making it more productive, perhaps explaining the persistence of Hollywood or Wall Street. With the accelerated pace of innovation taking place across many industries, physical proximity to the major players continues to have value.

\footnotetext{
2 There is some debate on the extent to which Tokyo and Paris are monocentric. See Garcia-Lopez (2019) and Rodrigue et al. (2017).

3 The following three paragraphs are from Agarwal et al. (2012).
} 
Third, theories of urban growth recognize that congestion costs may eventually deter growth. These costs may be in the form of transportation congestion, congested public services, or very high rents or wages. At some point, the marginal firm will locate elsewhere-in another city, or somewhere outside the city center. If the transport network offers many locations with good accessibility, it is reasonable to expect that smaller centers will appear, taking advantage of the regional agglomeration economies (labor supply, public infrastructure, overall employment mix, etc.), as well as the external benefits of specific locations. A related point is consistent with declining agglomeration economies: if agglomeration economies are limited, then smaller clusters (with less congestion and lower rents than the CBD) located at the more accessible nodes of the transportation network are logical outcomes.

As with the earlier discussion of agglomeration economies on the consumer side, similar arguments can be made that external benefits exist at the sub-metropolitan scale. Christaller's theory (1966) is based on consumers benefit from localized clusters of shopping opportunities (retail districts, shopping malls, auto rows). Although Glaeser et al. (2001a, b) consider "consumer city" benefits at the metropolitan scale, one of the great attractions of large cities is the diversity of opportunities, which often are identified at the neighborhood or district level: Koreatown (Los Angeles), the Castro District (San Francisco), or Little India (New York). The Florida (2002) and Kotkin (2000) arguments about the importance of amenities for knowledge workers are also relevant; places that attract highly educated workers tend to be geographically specific, for example SoHo in New York City, or downtown Santa Monica in Los Angeles. These are areas with concentrations of unique restaurants, shops, and places to see and be seen.

\subsection{Empirical evidence}

Agarwal et al. (2012) argued that polycentricity provides evidence of agglomeration economies at the sub-metropolitan level. Using data from the Los Angeles metropolitan area, we showed that (1) over a 20-year period, 1980-2000, there is no evidence of polycentricity declining; (2) industry mix within centers is different than industry mix outside centers, and (3) centers tend to be located in areas of higher network accessibility. Others have shown the persistence of polycentricity in the case of Chicago (McMillan and Lester 2003), and the economic heterogeneity of subcenters in Houston (Craig et al. 2016) and Chicago (Yang et al. 2019). These results suggest that the value of agglomeration economies at the sub-metropolitan level remains high. As expected, some industries find proximity more valuable than others, and hence, there is spatial differentiation across industry sectors. Like a system of cities, these centers tend to emerge where access to the regional transport network is high, allowing for interactions between centers.

There is a literature on agglomeration economies within metropolitan areas. Rosenthal and Strange tested for agglomeration effects at the zip code, county, and state level for the manufacturing sector and found significant effects at the zip code level. Rosenthal and Strange (2003) used measures of firm growth in six different manufacturing sectors, again at the zip code level, and found strong localization 
effects for some of the sectors. Other studies have examined high tech firms in Texas (De Silva and Mccomb 2011), and agglomerations of producer services inside and outside the CBD (Drennan and Kelly 2011). However, none of these studies considers employment centers or clusters of different types of economic activity. These studies do not tell us about the nature of these concentrations or their spatial and functional relationships.

\subsection{Employment centers}

A different thread of literature focuses on employment centers. In economic theory, multiple centers emerge when agglomeration costs (wages, rents) exceed benefits, leading new firms to seek lower cost locations (Anas et al. 1998). An employment center is defined as a cluster of activity of sufficient magnitude to influence land prices and hence spatial form. In theory, identifying centers in a polycentric area is straightforward: any cluster that independently influences land values constitutes a center. However, the reality of urban spatial structure makes identification of employment centers challenging. Over the past nearly three decades many methods of identification have been used. Although the method does affect the number and size of identified centers, studies clearly show multiple employment centers in metropolitan areas throughout the USA. ${ }^{4}$

\section{Los Angeles region case study}

The Los Angeles region is among the most polycentric of all US metropolitan areas as measured by the number of centers and the relative importance of the CBD (Lee 2007). Multiple employment centers make it possible to test hypotheses on agglomeration economies. The Los Angeles region is the second largest US Combined Statistical Area (CSA), with 2010 population of about 18 million and employment of about 7 million. The region includes five counties covering $88,048 \mathrm{~km}^{2}$. It is a global trade hub: the twin ports of Los Angeles and Long Beach are the largest container ports in the USA and account for about $40 \%$ of all US imports. It has the nation's second busiest airport, and the Los Angeles-Long Beach MSA is routinely ranked first in the USA for traffic congestion.

\subsection{Persistence}

The first question to address is whether we have evidence that agglomeration economies are changing over time. Traffic congestion in the region has greatly increased due to regional population and employment growth, as well as any increase in agglomeration. The Texas Transportation Institute index of hours of delay per commuter increased $60 \%$ from 1982 to 2014 . All else equal, increased congestion should

\footnotetext{
${ }^{4}$ For a recent review, see Agarwal et al. (2012).
} 


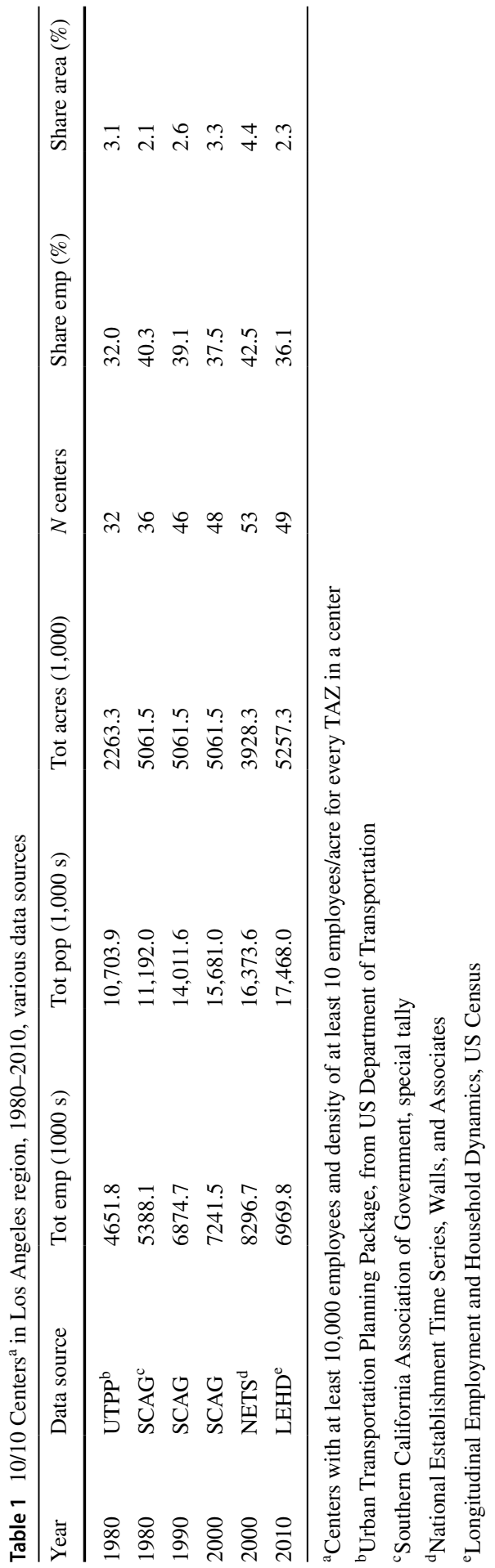


result in a decline in agglomeration. Giuliano and colleagues have been studying the polycentricity of the Los Angeles region for nearly three decades. We have tracked Los Angeles region urban form using various data sources but a consistent method of identifying employment centers.

Table 1 shows results over a 30-year period, from 1980 to 2010. Centers are defined as a collection of spatial units that together have at least 10,000 employees and a density of at least 10 employees/acre (Giuliano and Small 1991). The density cutoff corresponds to the 95th percentile of the cumulative employment density distribution in 2000. The region has grown enormously in population (63\%). There were major economic expansions and recessions over the 30 years, most recently the Great Recession of 2008. While the population numbers are comparable (all come from US Census data), the employment numbers are not, as can be seen in the 1980 and 2000 results using different data. The first study (Giuliano and Small 1991) used journey to work data then provided by the US Department of Transportation (DOT). A later longitudinal study (Giuliano et al. 2007) used custom data created by the regional metropolitan planning organization (MPO), and the two decades of these data are fully internally comparable. Giuliano et al. (2015) conducted a second longitudinal study using the proprietary National Establishment Time Series (NETS) data, and most recently have used employment data produced by the US Census (Giuliano et al. 2018). The differences in geographic size are due to different definitions of urbanized areas.

Despite these differences, there is strong evidence of persistence. The number of centers trends upward. The share of employment within centers ranges between 32 and $42 \%$, but there is no clear trend. The centers consistently account for just 2 to $4 \%$ of the land area of the region, a remarkable level of concentration. Despite the increase in traffic congestion over this period, it appears that sub-metropolitan agglomeration continues to be a net benefit to many industry sectors.

While the numbers in Table 1 support persistence, they do not provide information on spatial consistency. Do centers remain in the same places over time? Given the longevity of the built environment, we would expect a high degree of consistency even over 30 years. Figure 1 maps the 10/10 centers in 1980 and 2010. We recreated Fig. 3a in Giuliano et al. (2007). Figure 1 shows a mixed picture. The largest centers are consistent, and most of the centers existing in 1980 also exist in 2010. Difference among the smaller centers is likely in part matter of using different data sources and an arbitrary cutoff for center definition, which would affect smaller centers more than larger centers. The loss of centers in the core area is consistent with the decline of the aerospace industry in the 1990s. The emergence of new centers is consistent with the areas of the region that have experienced the most growth of population and employment. There appears to be a trend of decentralization within the centers themselves.

\subsection{Agglomeration economies}

The second question is whether centers still exhibit various types of agglomeration economies. We use 2010 data to explore attributes of employment centers and link them to elements of agglomeration economies. 


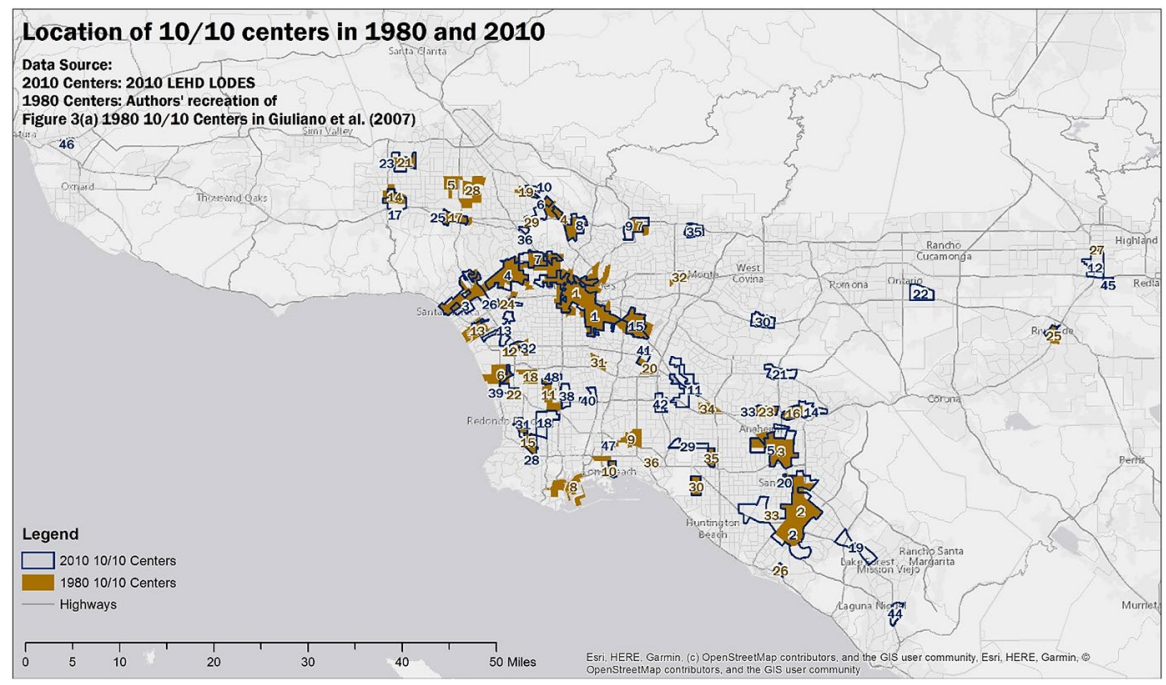

Fig. 1 Location of 10/10 centers in 1980 and 2010. 10/10= at least 10,000 employees and average density of at least 10 employees/acre

We use the 2010 Longitudinal Employer-Household Dynamics (LEHD) which provides employment counts in two-digit North American Industry Classification System (NAICS) industry sectors at the census tract level. All employment except uniformed military, self-employed workers, and informally employed workers are included in LEHD. The data sources of LEHD are Unemployment Insurance wage data, the Quarterly Census of Employment in Wages, and the Office of Personnel Management data. In order to link employment data with the transportation network, the data were converted from census tract geography to Transportation Analysis Zones (TAZs). TAZs are spatial units that are approximately the same size as census tracts, but avoid boundaries that follow major roadways. Cleaning for missing data and excluding sparsely populated areas resulted in 3789 TAZs for analysis.

\subsubsection{Identifying employment centers}

We use the Giuliano and Small (1991) method for identifying employment centers. We use two categories of centers that, respectively, correspond to the 90th and 95th percentiles of the employment density distribution: TAZs that together have a job density equal to or greater than 10 employees per acre and at least 10,000 employees, and TAZs that together have a job density equal to or greater than 20 employees per acre and at least 20,000 employees. They are called 10/10 and 20/20 centers, respectively. The more restrictive definition captures only the largest and most dense employment concentrations, which should be more specialized than the 10/10 centers. 


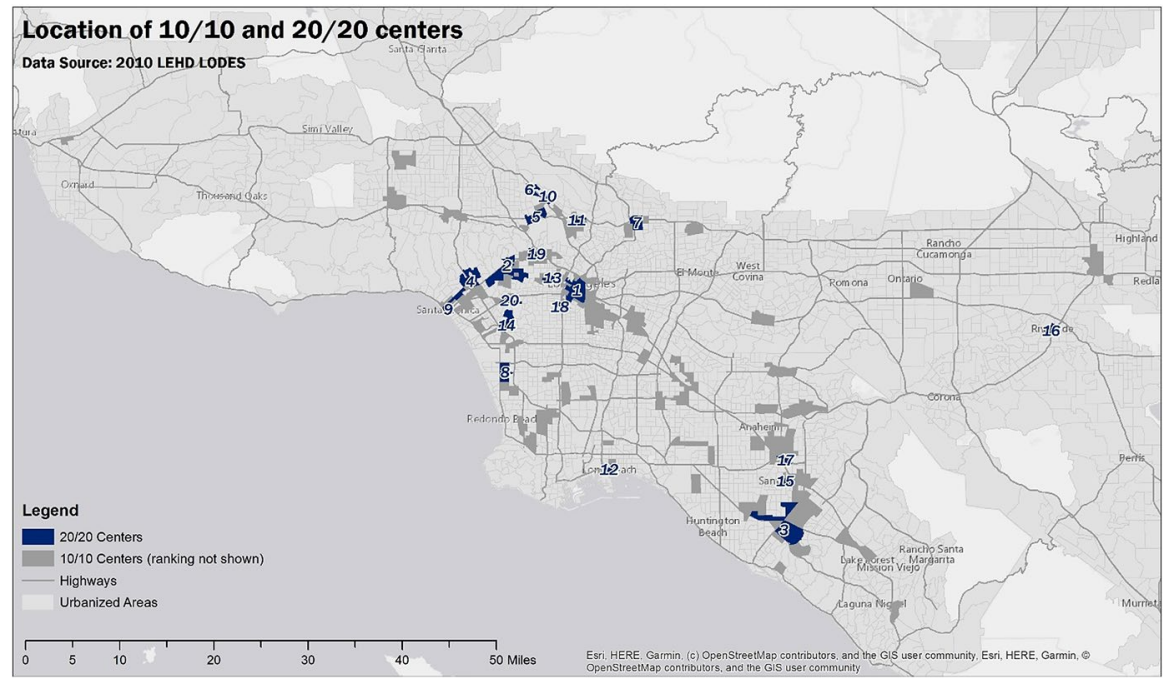

Fig. 2 Location of 10/10 and 20/20 centers, 2010 data. 10/10=at least 10,000 employees and average density of at least 10 employees/acre; 20/20=at least 20,000 employees and average density of at least 20 employees/acre

Table 2 Characteristics of $10 / 10$ and $20 / 20$ centers

\begin{tabular}{|c|c|c|c|c|}
\hline \multirow[t]{2}{*}{ Employment } & \multicolumn{2}{|l|}{$10 / 10^{\mathrm{a}}$} & \multicolumn{2}{|l|}{$20 / 20^{\mathrm{b}}$} \\
\hline & $N$ of centers & $\begin{array}{l}\text { Ave density } \\
\text { (emp/acre) }\end{array}$ & $\mathrm{N}$ of centers & $\begin{array}{l}\text { Ave density } \\
\text { (emp/acre) }\end{array}$ \\
\hline $100-500 \mathrm{~K}$ & 6 & 41.8 & 3 & 99.4 \\
\hline $50-100 \mathrm{~K}$ & 4 & 21.5 & 4 & 54.1 \\
\hline $20-50 \mathrm{~K}$ & 20 & 20.8 & 13 & 48.7 \\
\hline $10-20 \mathrm{~K}$ & 19 & 15.5 & N/A & N/A \\
\hline Total number of centers & 49 & & 20 & \\
\hline Total employment in centers & $2,521,110$ & & $1,239,265$ & \\
\hline Share employment in centers & $36.1 \%$ & & $17.8 \%$ & \\
\hline
\end{tabular}

${ }^{\mathrm{a}}$ Centers with at least 10,000 employees and density of at least 10 employees/acre for every TAZ in a center

${ }^{\mathrm{b}}$ Centers with at least 20,000 employees and density of at least 10 employees/acre for every TAZ in a center

Figure 2 maps the centers, and Table 2 gives basic descriptive information on the centers. Figure 2 is the same as Fig. 1, but shows both 10/10 and 20/20 centers for 2010 only. The 10/10 centers are colored in gray, and the 20/20 centers are colored in navy. The concentrations discussed above are clear.

Table 2 shows that the 10/10 centers account for about twice the share of employees as the 20/20 centers. Given that 10/10 centers and 20/20 centers occupy only $3.6 \%$ and $0.8 \%$ of the total land area, respectively, the concentration of employees in 
Table 3 Industry shares inside and outside centers, 10/10 and 20/20 centers, column percentages

\begin{tabular}{lcccc}
\hline Sector & $\begin{array}{l}10 / 10 \text { cent- } \\
\text { ers }(\%)\end{array}$ & $\begin{array}{l}\text { Outside } 10 / 10 \\
\text { centers }(\%)\end{array}$ & $\begin{array}{l}20 / 20 \text { cent- } \\
\text { ers }(\%)\end{array}$ & $\begin{array}{l}\text { Outside 20/20 } \\
\text { centers (\%) }\end{array}$ \\
\hline Utilities & 0.5 & 0.6 & 0.6 & 0.6 \\
Construction & 2.2 & 4.6 & 0.9 & 4.5 \\
Manufacturing & 8.9 & 5.9 & 3.8 & 6.3 \\
Wholesale trade & 5.5 & 3.9 & 3.7 & 4.1 \\
Retail trade & 9.5 & 12.5 & 7.7 & 12.4 \\
Transportation and warehousing & 2.4 & 2.6 & 2.0 & 2.6 \\
Information & 5.9 & 1.4 & 10.0 & 1.5 \\
Financial activities & 5.1 & 2.6 & 5.5 & 2.8 \\
Real estate and rental and leasing & 2.2 & 2.0 & 2.2 & 2.0 \\
Professional and business services & 8.2 & 4.4 & 11.3 & 4.5 \\
Management of companies and enterprises & 1.6 & 0.8 & 1.7 & 0.8 \\
Administrative and support & 7.6 & 5.3 & 7.2 & 5.5 \\
Educational services & 6.9 & 13.8 & 7.1 & 13.3 \\
Health care and social assistance & 11.9 & 11.6 & 13.2 & 11.5 \\
Arts, entertainment, and recreation & 2.2 & 2.0 & 2.3 & 2.0 \\
Accommodation and food services & 8.3 & 10.7 & 8.5 & 10.6 \\
Other services & 6.4 & 12.0 & 4.8 & 11.7 \\
Public administration & 4.6 & 1.9 & 6.8 & 2.0 \\
\hline
\end{tabular}

Table is based on total employment in the LA urbanized area by two-digit sector

these centers is quite high. Among both groups, there are no centers with more than 500,000 employees, and most of them have less than 50,000 employees. The average job density decreases with the size of center. The average density for 100-500 K centers is almost twice of that for $50 \mathrm{~K}-100 \mathrm{~K}$ centers, but the differences are much smaller between $50-100 \mathrm{~K}$ and $20-50 \mathrm{~K}$ centers.

\subsubsection{Specialization}

Theory suggests that industry composition within centers should be different from composition outside centers. Industries vary in the extent to which agglomeration generates external benefits. For example, population serving activity (e.g., general retail) places a high value on access to customers who are more widely distributed across the metro area than employment. Professional services, on the other hand, value access to existing and potential clients and should be more likely to cluster.

As a first comparison, Table 3 gives industry shares inside and outside centers for the two groups of centers. The gray shading highlights sectors that are more concentrated in centers, and the blue shading highlights sectors that are less concentrated in centers. Both groups of centers are more specialized in sectors including information, financial activities, professional and business services, management of companies and enterprises, administrative and support, and public administration industry sectors as compared to areas outside of these centers. Many of these are 
the traditional information-based services that we argued above should be highly reliant on agglomeration economies. Population serving activities (retail, education, and other services) are less concentrated in centers. The 20/20 centers show a higher degree of specialization, as expected. Manufacturing is of particular note: it is more concentrated in the 10/10 centers, but less concentrated in the 20/20 centers, reflecting the effect of higher density and land rents. Given that manufacturing is generally more land intensive than services, it makes sense that manufacturing would cluster in smaller, lower density centers. Wholesale trade shows the same pattern. Transportation is slightly less concentrated in both groups of centers.

\subsubsection{Sharing}

Another aspect of agglomeration is the sharing of resources across industry sectors. It is possible that centers play different roles in the regional economy. We found evidence of center specialization in our first study of employment centers in Los Angeles using 1980 data (Giuliano and Small 1991). Using hierarchical cluster analysis, we identified five clusters: specialized manufacturing, mixed industrial, mixed service, specialized entertainment, and specialized service. Does such specialization still exist three decades later? We conducted cluster analysis on both sets of 2010 centers. We used K-means cluster analysis and identified five groups of centers in both cases.

Table 4 shows the number of 10/10 centers in each cluster group with some examples and provides brief descriptions of each group. For comparison, the 1980 cluster groups from Giuliano and Small (1991) are also presented. Most of the 2010 centers are in Groups 1 and 3. The 2010 clusters are similar to those of 1980. Groups 1 and 2 correspond to "mixed service." Many of the centers are historically independent cities, including Santa Monica, Pasadena, Glendale, and Anaheim. Group 3 corresponds to "specialized manufacturing" and includes older heavy manufacturing zones (Commerce) as well as newer light manufacturing (Irvine). In 1980, there were two groups of manufacturing centers, one with more heavy manufacturing. This group disappears in 2010, reflecting the structural change in the regional economy. Group 4 corresponds to "specialized entertainment," but reflects the increased concentration of media in the Culver City area. The differences from 1980 to 2010 seem to be due to the general decline in manufacturing and increase in services, as well as the emergence of new mixed centers in suburban areas.

Figure 3 shows the distribution of groups of 10/10 centers. The crescent from downtown LA to Santa Monica is composed of a string of Group 1 centers; this is the highest density corridor in the region. There are no Group 3 centers in the corridor. The large Group 2 center (center 1 on map) includes Downtown LA and the old industrial zone following the I-5 freeway. Group 4 centers (information and media) are the locations of most studios and entertainment media firms.

Prior research suggests that agglomeration benefits vary across industries. Do we observe such variation at the sub-metropolitan level? Ideally, we would estimate density gradients to test whether the cluster groups have significantly different structures. However, the centers are too close together to be able to meaningfully estimate a density gradient. We therefore use a simple alternative; the 


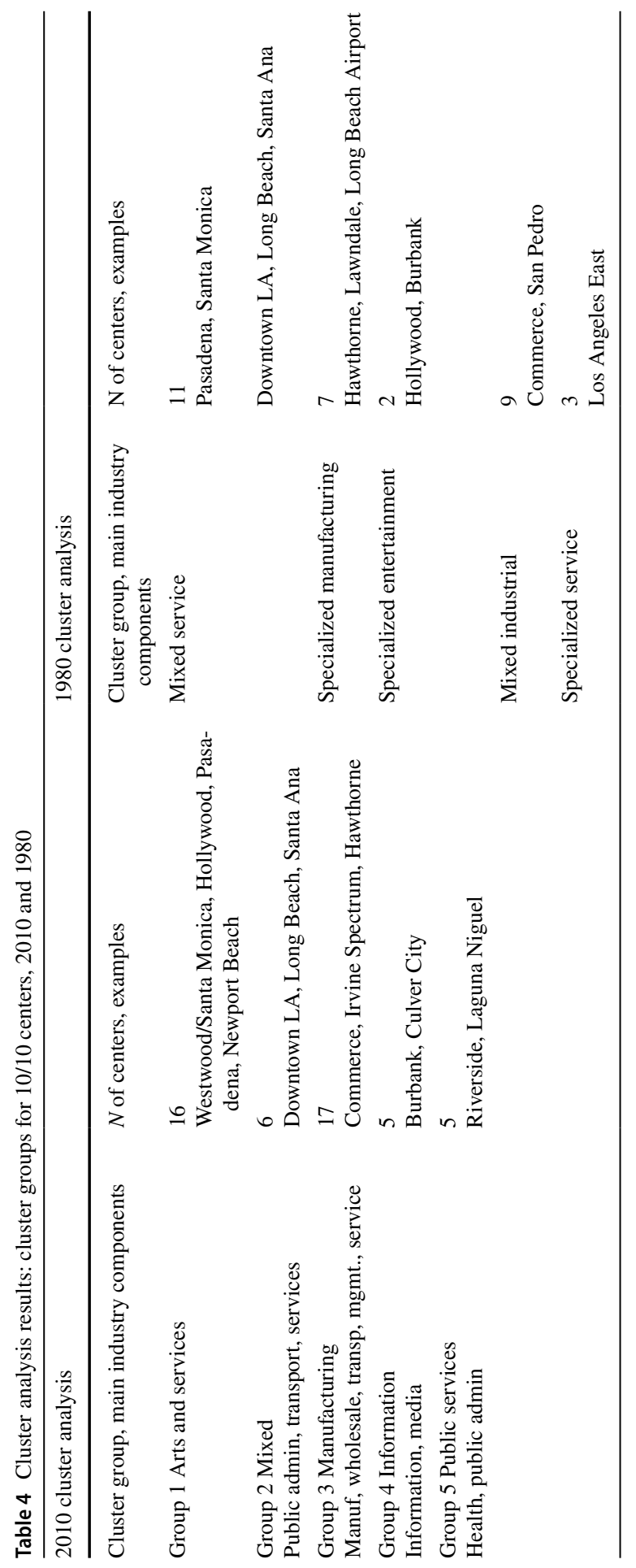




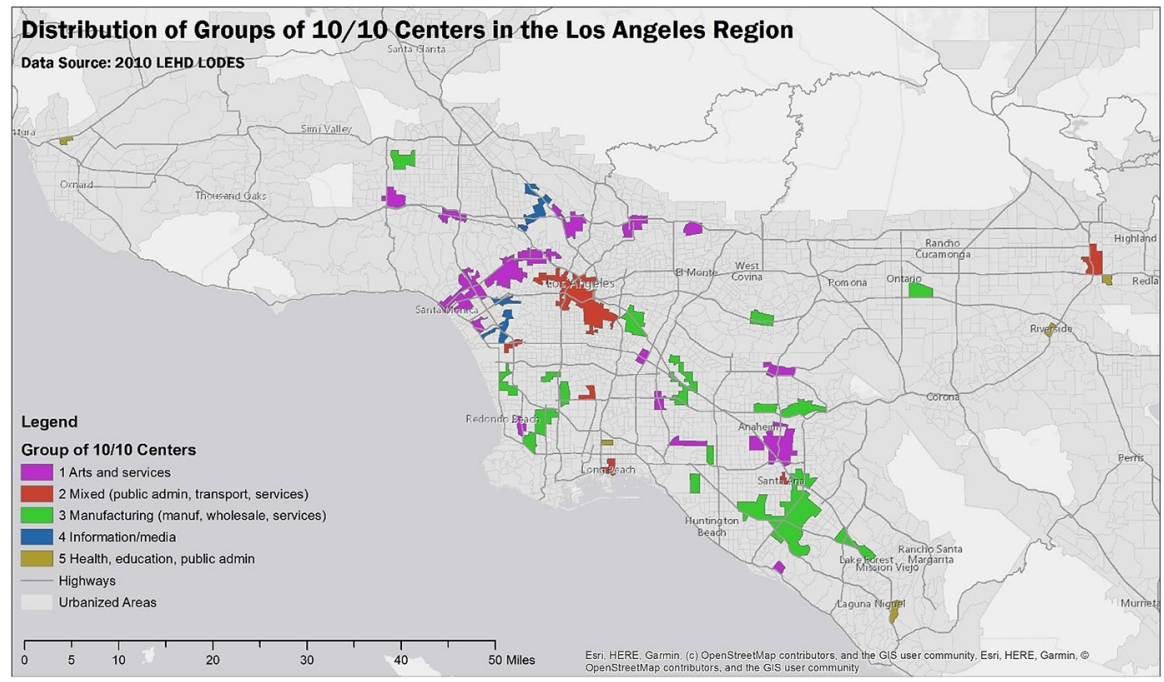

Fig. 3 Location of 10/10 centers by cluster group

Table 5 Average size and density by cluster group, 10/10 centers

\begin{tabular}{lclll}
\hline Group & $\begin{array}{l}\text { Number of } \\
\text { centers }\end{array}$ & $\begin{array}{l}\text { Average size (number of } \\
\text { employees per center) }\end{array}$ & $\begin{array}{l}\text { Average density } \\
\text { (emp/acre) }\end{array}$ & $\begin{array}{l}\text { Average peak } \\
\text { density } \\
\text { acre) }\end{array}$ \\
\hline 1. Arts and services & 16 & 56,589 & 29.1 & 60.7 \\
2. Mixed & 6 & 92,670 & 29.1 & 132.4 \\
3. Manufacturing & 17 & 43,745 & 14.7 & 15.9 \\
4. Information/media & 5 & 48,624 & 37.4 & 77.2 \\
5. Public services & 5 & 14,571 & 22.3 & 24.9 \\
\hline
\end{tabular}

${ }^{\mathrm{a}}$ Average peak density $=$ average of the densities of the highest density TAZ of each center

average and peak density of the groups. Table 5 gives average size and density for the five groups of centers. In terms of size, the mixed centers are the largest and the public services centers are the smallest. The mixed centers include downtown Los Angeles, which is the largest center (408,000 employees) and has the highest peak density (575 employees/acre). The manufacturing centers are distinct for relatively low density. None of them are located in the high density crescent of centers to the west and south of downtown Los Angeles. In contrast, the information centers have the highest average density. These results are consistent with the different types of agglomeration economies. Manufacturing firms share infrastructure (all manufacturing centers are on or adjacent to at least one freeway), labor, and input suppliers. The higher average density of information centers suggests more emphasis on learning and knowledge exchange. 
Table 6 20/20 centers by cluster group

\begin{tabular}{|c|c|}
\hline Cluster group & Centers $^{\mathrm{a}}$ \\
\hline Group A: Mixed & 5 \\
\hline $\begin{array}{l}\text { Info, professional services, accom- } \\
\text { modation, manufacturing, transport }\end{array}$ & $\begin{array}{l}\text { Wilshire West (2), LAX (8), Santa Monica (9), Long Beach (12), } \\
\text { Hollywood (19) }\end{array}$ \\
\hline Group B: Education & 2 \\
\hline Education, health & Westwood (4), LA South (18) \\
\hline Group C: Information & 5 \\
\hline Information, media & $\begin{array}{l}\text { Burbank (5), Burbank North (6), Burbank East (10), Culver City } \\
\text { South (14), Culver City (20) }\end{array}$ \\
\hline Group D: Public services & 2 \\
\hline Public admin, health & Santa Ana (15), Riverside (16) \\
\hline Group E: Business service & 6 \\
\hline Retail, professional, finance & $\begin{array}{l}\text { LA downtown (1), Irvine/SNA (3), Pasadena (7), Glendale (11), } \\
\text { Wilshire East (13), Orange (17) }\end{array}$ \\
\hline
\end{tabular}

${ }^{\mathrm{a}}$ Number indicates rank by total employment



Fig. 4 Location of 20/20 centers by cluster group

Table 6 gives the cluster groups for 20/20 centers. ${ }^{5}$ Names of all the centers are listed, and the rank order (by total employment) is given in parentheses. The center is mapped and color coded in Fig. 4. The small number of centers results in small cluster groups: groups B and D have only two centers each. Group B includes the

\footnotetext{
5 Comparison with 1980 is not possible, as cluster analysis of 1980 20/20 centers was not conducted because of the small number of $20 / 20$ centers.
} 
Table 7 Average size and density of centers by cluster group, 20/20 centers

\begin{tabular}{lllll}
\hline Group & $\begin{array}{l}\text { Number of } \\
\text { centers }\end{array}$ & $\begin{array}{l}\text { Average size (number of } \\
\text { employees) per center }\end{array}$ & $\begin{array}{l}\text { Average density } \\
\text { (emp/acre) }\end{array}$ & $\begin{array}{l}\text { Average peak } \\
\text { density } \\
\text { acre) }\end{array}$ \\
\hline A: Mixed & 5 & 59,111 & 28.0 & 77 \\
B: Education & 2 & 56,354 & 32.8 & 235 \\
C: Information & 5 & 40,698 & 31.6 & 76 \\
D: Public services & 2 & 27,751 & 38.5 & 60 \\
E: Business services & 6 & 95,335 & 34.2 & 145 \\
\hline
\end{tabular}

UCLA and USC areas, with their large number of education and medical employees they end up in a separate cluster. Group D includes Santa Ana and Riverside, both older cities with relatively little private employment. The information cluster, Group $\mathrm{C}$, includes all of the locations known for media and entertainment production. The composition of the cluster groups changes, as the industry sectors more sensitive to the negative externalities of agglomeration (land price, wage price, or congestion) are eliminated. For example, there is no manufacturing cluster. Some of the larger manufacturing centers remain as mixed centers. Apparently, manufacturing is located in the lower density areas of the 10/10 centers.

Interestingly, we do not observe the differentiation of average or peak density as we did with the 10/10 centers; see Table 7 . If we disregard groups B and D, the information centers now are in the middle for average density and comparable to group A for peak density. Group E is dominated by downtown Los Angeles, which is again the largest center (306,000 employees) and has the highest average density (76 employees/acre). Thus, the averages for group E are skewed by LA downtown. The sectors concentrated in the most dense and largest centers must value agglomeration benefits enough to overcome the added costs. However, our two-digit industry codes are not sufficient to differentiate what specific sectors locate in such centers. We do know that the 20/20 centers are more specialized; they are heavily oriented to financial, professional, and management services.

\subsubsection{Labor pooling}

Another dimension of agglomeration economies is labor pooling. We do not have information on commute sheds for the centers, but given the close proximity of most centers, it seems reasonable to expect that commute sheds overlap. Figure 5 maps the 10/10 centers on a labor force accessibility surface. It is calculated as the number of persons available within a 30 min network travel time by private vehicle from any given zone. Network travel time is based on the Southern California Association of Governments 2012 base year calibrated network. Accessibility is given in quintiles, with the darkest shading representing the highest level of accessibility. As expected, labor force access is highest in the historical core of the region, but it remains quite high throughout Los Angeles and Orange counties. Most centers are located within the top two quintiles of labor force access. Centers locate in areas of lower labor 


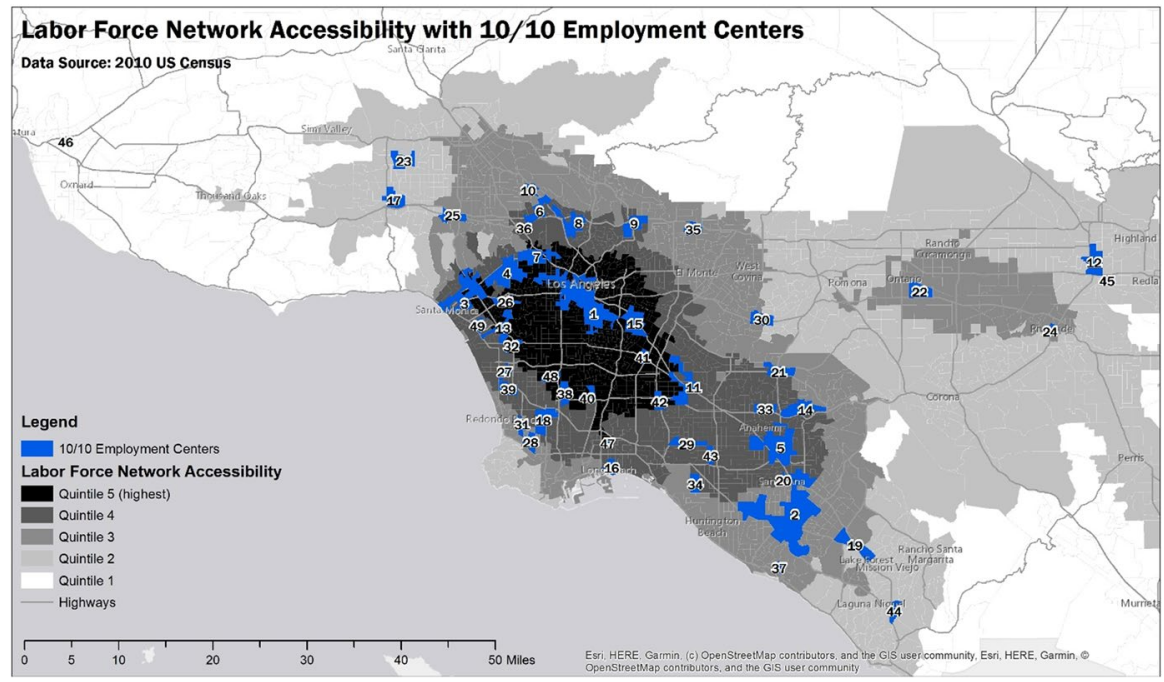

Fig. 5 Network accessibility and location of 10/10 centers, with centers numbered in rank order by size (total employees)

force access are small, with the exception of the Irvine/Santa Ana center (center 2 on the figure). It would appear that centers are sharing a common labor pool, and that labor pooling benefits work at the regional level.

\subsection{Observations on the Los Angeles case study}

The Los Angeles case study shows both the persistence of employment centers over time and presence of various aspects of agglomeration economies at the sub-metropolitan level. First, employment centers not only have persisted over three decades, but have remained quite stable, despite significant population and employment growth. There is a mild increasing trend in the number of centers, as would be expected in a growing regional economy, but no trend in average density. The degree of employment concentration is rather remarkable, given the perception of Los Angeles as the epitome of sprawl.

Second, not only do employment centers continue to exist, they display specialization both respect to employment outside centers and between centers. The types of industry sectors associated with agglomeration are more concentrated inside centers than outside centers, and the degree of concentration is higher for the larger, more dense centers. Centers appear to serve different roles in the space economy, some serving as specialized service centers, others still reflecting their function as downtowns of smaller cities now absorbed into the regional economy, and some, for the $10 / 10$ centers, serving as manufacturing centers.

Third, the case study suggests both local and regional agglomeration economies. Large portions of the labor force are available to multiple centers. The regional 
transport network, especially the freeway system, provides access between centers. Using Puga's categories of sharing, matching, and learning, we have been able to identify evidence to support all three categories.

\section{Conclusions}

Agglomeration economies have been widely documented at both the regional and sub-regional levels. The presence of local agglomeration economies explains the persistence of employment centers over time and suggests that polycentric cities are enduring, even in the information age. Multiple centers with multiple attributes give firms choices. At the same time, regional agglomeration economies in the form of infrastructure and labor force sharing are available to every center. Enhanced choices should increase productivity.

The interplay of agglomeration at different geographic levels suggests a highly complex and connected space economy. Large metropolitan areas have the advantage of scale, offering a highly diverse and specialized labor force, dense networks of intermediate suppliers, and extensive transport and communication systems. The presence of multiple centers likely lowers the land, wage, and congestion costs of agglomeration by geographically spreading economic activity while still preserving agglomeration benefits. It is possible that the presence of multiple centers facilitates metropolitan growth and is one explanation for the emergence of mega-regions.

A case study of one metropolitan area offers some interesting insights into the structure of space economies, but is a long way from providing systematic evidence. Similar research on other large metro areas is an obvious next step. Although comparable employment data at fine geographic scale over many decades are difficult if not impossible to find, much could be done via cross-sectional studies, or studies that span shorter periods of time. Meanwhile, it seems clear that employment centers-and their influence on urban spatial structure - are here to stay.

Acknowledgements Research presented in this paper was supported by grants from the US Department of Transportation and the Volvo Research and Education Foundation. This paper evolved from Genevieve Giuliano's Presidential Address delivered at the 2019 meetings of the WRSA in Napa, California. Comments from discussant Peter Gordon and an anonymous reviewer are gratefully acknowledged. All errors and omissions are the responsibility of the authors.

\section{References}

Agarwal A, Giuliano G, Redfearn CL (2012) Strangers in our midst: the usefulness of exploring polycentricity. Ann Reg Sci 48:433-450

Anas A, Arnott R, Small K (1998) Urban spatial structure. J Econ Lit 36:1426-1464

Audirac I (2005) Information technology and urban form: Challenges to smart growth. Int Reg Sci Rev 28(2):119-145

Backman M, Kohlhase J (2013) The influence of diversity on the formation, survival and growth of new firms. Working paper series in economics and institutions of innovation 337, Royal Institute of Technology, CESIS - Centre of Excellence for Science and Innovation Studies

Cairncross F (1997) Death of distance: how the communications revolution will change our lives. Harvard Business School Press, Boston 
Castells M (1989) The informational city: information technology, economic restructuring and the urbanregional process. Blackwell, Cambridge

Castells M, Hall P (1994) Technopoles of the world: the making of the twenty-first century industrial complex. Routledge, London

Christaller W (1966) Central places in Southern Germany. Prentice-Hall, Englewood Cliffs

Coles MG, Smith E (1998) Marketplaces and matching. Int Econ Rev 39(1):239-255

Costa DL, Kahn ME (2000) Power couples: changes in the locational choice of the college educated, 1940-1990. Quart J Econ 115(4):1287-1315

Craig S, Ng P (2001) Using quantile smoothing splines to identify employment subcenters in a multicentric urban area. J Urban Econ 49:100-120

Craig S, Kohlhase J, Perdue A (2016) Empirical polycentricity: the complex relationship between employment centers. J Reg Sci 56(1):25-52

De Silva D, Mccomb R (2011) Geographic concentration and firm survival. https://doi.org/10.2139/ Ssrn. 1912506

Downs A (1997) The challenge of our big cities. Hous Policy Debate 8(2):359-408

Drennan M, Kelly H (2011) Measuring urban agglomeration economies with office rents. J Econ Geogr 11(3):481-507

Duranton G, Puga D (2001) Nursery cities: urban diversity, process innovation, and the life cycle of products. Am Econ Rev 91(5):1454-1477

Duranton G, Puga D (2004) Micro-foundations of urban agglomeration economies. In: Henderson V, Thisse J-F (eds) Handbook of regional and urban economics, vol 4. North-Holland, Amsterdam, pp 2119-2171

Ellison G, Glaeser EL, Kerr W (2010) What causes industry agglomeration? Evidence from coagglomeration patterns. Am Econ Rev 100(3):1195-1213

Fathy T (1991) Telecity: information technology and its impacts on city form. Prager, London

Finney M, Kohlhase J (2008) The effect of urbanization on labor turnover. J Reg Sci 48(2):311-332

Florida R (2002) The rise of the creative class: and how it's transforming work, leisure, community and everyday life. Basic Books, New York

Florida R (2014) The rise of the creative class-revisited. Basic Books, New York

Forestall R, Greene R (1997) Defining job concentrations: the Los Angeles case. Urban Geogr 18(8):705-739

Garcia-López M-À (2010) Population suburbanization in Barcelona, 1991-2005: is its spatial structure changing? J Hous Econ 19(2):119-132

Garcia-Lopez MA (2019) All roads lead to Rome...and to sprawl? Evidence from European cities. Reg Sci Urban Econ 79:103467

Gillespie A (1992) Communications technology and the future of the city. In: Breheny M (ed) Sustainable development and urban form. Pion, London, pp 67-77

Giuliano G, Small K (1991) Subcenters in the Los Angeles region. Reg Sci Urban Econ 21:163-182

Giuliano G, Redfearn C et al (2007) Employment concentrations in Los Angeles, 1980-2000. Environ Plan A 39(12):2935-2957

Giuliano G, Hou Y, Kang S, Shin E-J (2015) Accessibility, location and employment center growth. Final Report, Metrans Project 11-06. https://www.metrans.org/research/11-06-accessibility-location-andemployment-center-growth. Accessed 11 May 2019

Giuliano G, Kang S, Yuan Q, Shin E-J (2018) Understanding freight flows in cities I: Does density crowd out freight intensive activities? Presented at the VREF urban freight conference, Gothenburg

Glaeser E (1999) Learning in cities. J Urban Econ 46(2):254-277

Glaeser E, Kahn M, Arnott R, Meyer C (2001a) Decentralized employment and the transformation of the American City. Brookings-Wharton papers on urban affairs. Brookings Institution, Washington DC, pp 1-63

Glaeser EL, Kolko J et al (2001b) Consumer city. J Econ Geogr 1(1):27-50

Gordon P, Richardson H (1996) Beyond polycentricity: the dispersed metropolis, Los Angeles, 19701990. J Am Plan Assoc 62:289-295

Gottman J (1982) Urban settlements and telecommunications. Ekistics 302:411-416

Graham S, Marvin S (1996) Telecommunications and the city. Routledge, London

Holmes TJ (1999) Localization of industry and vertical disintegration. Rev Econ Stat 81(2):314-325

Jacobs J (1961) The death and life of great American cities. Random House, New York

Jaffe AB, Trajtenberg M, Henderson R (1993) Geographic localization of knowledge spillovers as evidenced by patent citations. Quart J Econ 108(3):577-598 
Kotkin J (2000) The new geography: how the digital revolution is reshaping the American landscape. Random House, New York

Krugman P (2011) The new economic geography, now middle-aged. Reg Stud 45(1):1-7

Lang RE, Lefurgy J (2003) Edgeless cities: examining the noncentered metropolis. Hous Policy Debate 14(3):427-460

Lee B (2007) "Edge" or "edgeless" cities? Urban spatial structure in US metropolitan areas, 1980 to 2000. J Reg Sci 47(3):479-515

Marshall A (1890) Principles of economics. Macmillan, London

McMillan D, Lester TW (2003) Evolving subcenters: employment and population densities in Chicago. J Hous Econ 12(1):60-81

McMillen D (2001) Nonparametric employment subcenter identification. J Urban Econ 50(3):448-473

Mitchell WJ (1996) City of bits: space, place and the infobahn. MIT Press, Boston

Muller P (2017) Transportation and urban form: stages in the spatial evolution of the American metropolis. In: Giuliano G, Hanson S (eds) The geography of urban transportation, 4th edn. The Guilford Press, New York, pp 57-85

Overman HG, Puga D (2010) Labor pooling as a source of agglomeration: an empirical investigation. In: Glaeser E (ed) Agglomeration economies. University of Chicago Press, Chicago, pp 133-150

Pascal A (1987) The vanishing city. Urban Stud 24:597-603

Puga D (2010) The magnitude and causes of agglomeration economies. J Reg Sci 50(1):203-219

Rauch R (1993) Productivity gains from geographic concentration of human capital: evidence from the cities. J Urban Econ 34(3):380-400

Redfearn C (2007) The topography of metropolitan employment: identifying centers of employment in a polycentric urban area. J Urban Econ 61(3):519-541

Rodrigue J-P, Dablanc L, Giuliano G (2017) The freight landscape: convergence and divergence in urban freight distribution. J Transp Land Use 10(1):557-572

Rosenthal S, Strange W (2001) The determinants of agglomeration. J Urban Econ 50(2):191-229

Rosenthal S, Strange W (2003) Geography, industrial organization, and agglomeration. Rev Econ Stat 85(2):377-393

Smith A (1776) An inquiry into the nature and causes of the wealth of nations. Printed For W. Strahan, and T. Cadell, Berlin

Webber M (1968) The post-city age. Daedalus 97(4):1091-1110

Yang T, Pan H, Hewings G, Jin Y (2019) Understanding urban subcenters with heterogeneity in agglomeration economies: Where do emerging commercial establishments locate? Cities 86:25-364

Publisher's Note Springer Nature remains neutral with regard to jurisdictional claims in published maps and institutional affiliations. 